
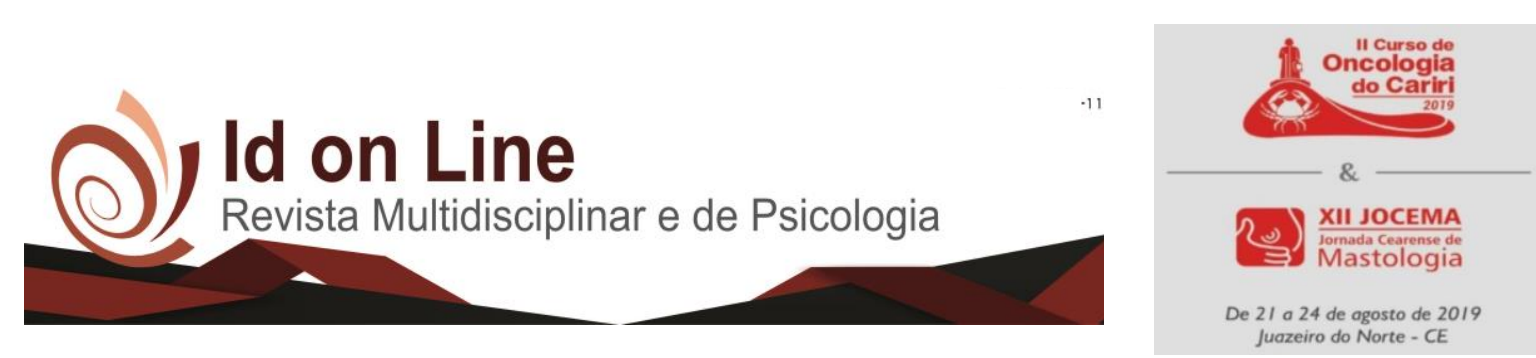

DOI: 10.14295/idonline.v13i46.1994

Resumo

\title{
RECONSTRUÇÃO MAMÁRIA COM PRÓTESE DE SILICONE APÓS MASTECTOMIA EM DECORRÊNCIA DE CÂNCER DE MAMA: REVISÃO SISTEMÁTICA
}

\author{
Bruna Raynara Novais Lima1; Rivania Beatriz Novais Lima²; Maria Josycley Novais Landim Soares ${ }^{3}$
}

Introdução: Segundo o Instituto Nacional de Câncer (2014), o câncer de mama é a segunda neoplasia mais comum no mundo e a mais frequente nas mulheres. De acordo com a Sociedade Brasileira de Mastologia (SBM, 2018 apud JOELI, 2018), devido ao diagnóstico tardio, 70\% desses cânceres recebem a mastectomia como solução. Após esta, parte do tratamento é a reconstrução mamária que é importante para o bem-estar da paciente. Assim, é necessário conhecer a reconstrução com a aplicação de prótese de silicone que, embora tenha seus pontos negativos, como possível contratura capsular ou infecção, possui melhor resultado estético e menores números de complicações após o procedimento (CAMMAROTA et al., 2018). Objetivo: Revisar a eficácia da reconstrução mamária com prótese de silicone. Método: Realizou-se uma revisão sistemática a partir da seleção de artigos na base de dados BVS. Foram analisados 15 artigos e selecionados 6 entre os anos de 2007 e 2018. Resultados: Ao contrário da utilização de próteses de silicone, as técnicas com material autólogo são associadas a mais casos de complicações e morbidade porque abrangem uma área doadora de tecido e uma receptora (CHAWLA et al., 2002). Segundo um estudo baseado na base de dados Perspective da Carolina do Norte, as taxas de complicação intra-hospitalar com a reconstrução mamária imediata à mastectomia foram maiores nos casos que utilizaram retalho miocutâneo do que implante ou nenhuma reconstrução $(15,2,4,0$ e $6,1 \%$, respectivamente, P <0,0001) (HERSHMAN et al., 2012). A reconstrução imediata à mastectomia é muito escolhida porque tem melhores resultados estéticos, é segura (não tem efeito em incidência de câncer), econômica e rápida, além de melhorar o estado psicológico da paciente (CORDEIRO, 2008; MURPHY et al., 2003). Contraindicações para essa ação incluem doença avançada (grau 3 ou superior), comorbidades médicas e radioterapia (RT) pós-operatória (HU; ALDERMAN, 2007). Quando há revestimento cutâneo suficiente, a reconstrução pode ser imediata com implante de silicone, quando isso não é possível, primeiro utilizam um expansor tecidual para depois colocar um implante permanente (CORDEIRO, 2008). A incidência de complicações é maior em doentes submetidos a RT após mastectomia, a taxa de complicações na reconstrução com prótese associada à RT é perto dos 50\%.(CHAWLA et al., 2002). Conclusão: A prótese de silicone é uma boa alternativa para melhorar a saúde feminina por apresentar eficácia estética e funcional.

Palavras-Chave: Reconstrução Mamária; Câncer de Mama; Prótese de Silicone.

\footnotetext{
1Discente do curso de medicina da Universidade Federal do Cariri. brunajuace@gmail.com;

2Discente do curso de medicina da Faculdade de Medicina do Juazeiro. rivania.bnovais@ gmail.com;

${ }^{3}$ Professora orientadora formada em medicina pela Universidade Federal de Campina Grande, com residência em Saúde da Família pela Universidade Federal do Cariri. drajosycleysoares@ gmail.com.
}

11 Id on Line Rev. Mult. Psic. V.13, N. 46 p. 11-12, 2019 - ISSN 1981-1179 EDICÃO ESPECIAL: ANAIS DO II CURSO DE ONCOLOGIA DO CARIRI E XII JOCEMA - JORNADA CEARENSE DE MASTOLOGIA. JUAZEIRO DO NORTE, 21 A 24 DE AGOSTO DE 2019.

Edição eletrônica em http://idonline.emnuvens.com.br/id 


\section{Referências:}

CAMMAROTA, Marcela Caetano et al. Breast reconstruction in young women and their peculiarities. Revista Brasileira de Cirurgia Plástica (rbcp) - Brazilian Journal Of Plastic Sugery, [s.1.], v. 33, n. 1, p.3-11, 2018. GN1 Genesis Network. http://dx.doi.org/10.5935/21771235.2018rbcp0002.

CHAWLA, Ashish K et al. Radiotherapy and breast reconstruction: complications and cosmesis with TRAM versus tissue expander/implant. International Journal Of Radiation Oncology*biology*physics, [s.1.], v. 54, n. 2, p.520-526, out. 2002. Elsevier BV. http://dx.doi.org/10.1016/s0360-3016(02)02951-6.

CORDEIRO, Peter G.. Breast Reconstruction after Surgery for Breast Cancer. New England Journal Of Medicine, [s.1.], v. 359, n. 15, p.1590-1601, 9 out. 2008. Massachusetts Medical Society. http://dx.doi.org/10.1056/nejmct0802899.

HERSHMAN, D. L. et al. Influence of health insurance, hospital factors and physician volume on receipt of immediate post-mastectomy reconstruction in women with invasive and non-invasive breast cancer. Breast Cancer Research And Treatment, [s.1.], v. 136, n. 2, p.535-545, 29 set. 2012. Springer Science and Business Media LLC. http://dx.doi.org/10.1007/s10549-012-2273-4.

HU, Emily; ALDERMAN, Amy K.. Breast Reconstruction. Surgical Clinics Of North America, [s.1.], v. 87, n. 2, p.453-467, abr. 2007. Elsevier BV. http://dx.doi.org/10.1016/j.suc.2007.01.004.

JOELLI AZEVEDO (Pernambuco). Cremep. Demora no Diagnóstico Resulta na Retirada da Mama em 70\% dos Casos de Câncer. 2018. Disponível em: <http://www.cremepe.org.br〉. Acesso em: 7 maio 2018.

MURPHY, Robert X. et al. Impact of Immediate Reconstruction on the Local Recurrence of Breast Cancer After Mastectomy. Annals Of Plastic Surgery, [s.1.], v. 50, n. 4, p.333-338, abr. 2003. Ovid Technologies (Wolters Kluwer Health). http://dx.doi.org/10.1097/01.sap.0000041488.88950.a2.

SOUSA, Juliana Cláudia Neves Martins de. Opções de Reconstrução mamária após Mastectomia total: indicações, vantagens e desvantagens. 2010. 38 f. Monografia (Especialização) -Curso de Medicina, Cirurgia Plástica, Universidade do Porto, Cidade do Porto, 2010. Cap. 4.

TEMPORÃO, José Gomes (Org.). Controle do Câncer de Mama: DOCUMENTO DE CONSENSO. Rio de Janeiro: Inca, 2004. 39 p. 